\title{
Influence of oxygen vacancies on magnetic and transport properties of thin $\mathrm{Zn}_{1-x} \mathrm{Co}_{x} \mathrm{O}_{y}$ films
}

\author{
Andrey A. Lotin ${ }^{1 *}$, Alina S. Kuz'mina ${ }^{2}$, Oleg A. Novodvorsky ${ }^{1}$, Liubov S. Parshina ${ }^{1}$, Olga D. Khramova ${ }^{1}$, Vladimir A. \\ Mikhalevsky ${ }^{1}$, Elena A. Cherebilo ${ }^{1}$, Alexander G. Shneider ${ }^{2}$, Nikolay S. Perov ${ }^{3}$, Liudmila A. Makarova ${ }^{3}$ \\ ${ }^{1}$ Federal Scientific Research Center "Crystallography and Photonics" RAS, 140700, Shatura, Russia \\ ${ }^{2}$ Irkutsk National Research Technical University, Irkutsk, Russia \\ ${ }^{3}$ Lomonosov Moscow State University, Moscow, Russia
}

\begin{abstract}
The features of the structural, transport and magnetic properties of thin $\mathrm{Zn}_{1-\mathrm{x}} \mathrm{Co}_{\mathrm{x}} \mathrm{O}_{\mathrm{y}}$ films $(\mathrm{x}=0$ $0.45)$, fabricated on $c$-sapphire substrates by the pulsed laser deposition method are studied. It is found that the transport and ferromagnetic properties of the wurtzite $\mathrm{Zn}_{1-\mathrm{x}} \mathrm{Co}_{\mathrm{x}} \mathrm{O}_{\mathrm{y}}$ films nonmonotonously depend on Co concentration at room temperature. For the $\mathrm{Zn}_{0.87} \mathrm{Co}_{0.13} \mathrm{Oy}$ film, the strongest ferromagnetic signal is observed that is caused by formation of the greatest number of metallic Co clusters. A further increase of doping impurity concentration in the films leads to the oxidation of metallic Co and formation of the paramagnetic $\mathrm{Co}_{3} \mathrm{O}_{4}$ phase, in consequence of which the ferromagnetic signal subsides.
\end{abstract}

\section{Introduction}

An opportunity to control the charge carrier and its spin provided rapid evolution of spintronics and development of new materials with semiconducting and magnetic properties, and, as a result, will lead to development of new information technologies. Zinc oxide is one of the most promising materials thanks to its unique properties. Being the direct gap semiconductor with a band gap width of $3.3 \mathrm{eV}$ and $n$-type conductivity zinc oxide is of great interest to applications in optoelectronics, solar energy, sensors and others [1]. Currently available theoretical estimations show that zinc oxide doped with $3 \mathrm{~d}$ transition metals can be ferromagnetic, with a Curie temperature above room temperature, which makes the material attractive for semiconductor spintronics $[1,2]$. However, the experimental results were rather contradictory. Some authors [3,4] watched gain of a ferromagnetic signal in $\mathrm{Zn}_{1-\mathrm{x}} \mathrm{Co}_{\mathrm{x}} \mathrm{O}$ films at increasing of cobalt concentration $(\mathrm{x})$ while other authors [5] report about nonmonotonous dependence. At present there is no single idea about the nature of a high-temperature ferromagnetism in thin $\mathrm{Zn}_{1-\mathrm{x}} \mathrm{Co}_{\mathrm{x}} \mathrm{O}_{\mathrm{y}}$ films.

Early we have already demonstrated the ferromagnetic properties of thin $\mathrm{Zn}_{1-\mathrm{x}} \mathrm{Co}_{\mathrm{x}} \mathrm{O}_{\mathrm{y}}$ films at room temperature [6]. The purpose of present paper is investigation of oxygen deficiency effect on structural, transport and magnetic properties of thin $\mathrm{Zn}_{1-\mathrm{x}} \mathrm{Co}_{\mathrm{x}} \mathrm{O}_{\mathrm{y}}$ films in the range of cobalt concentration from 0 to 45 at. $\%$.

\section{Experimental details}

\subsection{The synthesis of samples}

Thin $\mathrm{Zn}_{1-\mathrm{x}} \mathrm{Co}_{\mathrm{x}} \mathrm{O}_{\mathrm{y}}$ films $(\sim 200 \mathrm{~nm})$ were synthesized from high-purity $\mathrm{ZnO}-\mathrm{Co}_{3} \mathrm{O}_{4}$ ceramic targets by pulsed laser deposition method (PLD). Synthesis of films was carried out on $c$-sapphire substrates at $450{ }^{\circ} \mathrm{C}$ temperature [6]. The residual pressure in the vacuum chamber was $P \sim 5^{*} 10^{-6}$ Torr that provided an oxygen deficit in films up to $10 \%(0.9<\mathrm{y}<1)$ and, therefore, the electron conductivity [7] in the range of cobalt concentration $\mathrm{x}=0 \div 0.45$.

\subsection{Methods of sample research}

The transport properties of thin films have been investigated using Hall effect at the room temperature by the HSM 3000 measure system in the field of a permanent magnet of $1 \mathrm{~T}$. Study of crystal structure and phase compositions of thin $\mathrm{Zn}_{1-\mathrm{x}} \mathrm{Co}_{\mathrm{x}} \mathrm{O}_{\mathrm{y}}$ films have been conducted by the X-ray XRD 7000 diffractometer (Shimadzu) with $\mathrm{Cu} \mathrm{K} \alpha$ a radiation source $(\lambda=1.541 \AA)$. In order to verify the element composition the synthesized films were examined by EDS (Oxford Instruments X-Max 80, UK) and XPS (Physical Electronics PHI 5600, USA) using Al Ka radiation ( $h v=$ $1486.6 \mathrm{eV}$ ). Magnetic measurements were carried out by means of the vibrating sample magnetometer Lake Shore at the room temperature in the range of fields of $\pm 1.6 \mathrm{~T}$. The film magnetization was defined by subtraction of a magnetization signal of a clear substrate from the total magnetization signal of a sample (substrate + film).

The thickness of the films was measured with a modified microinterferometer MII-4 (LOMO, Russia). All measurements were carried out at the room temperature.

\section{Results and discussion}

\footnotetext{
* Corresponding author: lotin_82@mail.ru
} 
Fig. 1 illustrates the X-ray diffraction patterns of thin $\mathrm{Zn}_{1-\mathrm{x}} \mathrm{Co}_{\mathrm{x}} \mathrm{O}_{\mathrm{y}}$ films in semilogarithmic scale in the range of $2 \theta$-angles $30^{\circ}-50^{\circ}$. It is shown that the thin films retain the main phase of the wurtzite structure $\left(\mathrm{Pb}_{3} / \mathrm{mc}\right)$ indicated by the peaks at $34.4 ; 72.1 ; 123.8^{\circ} 2 \theta$ angles which correspond to the diffraction reflection orders from the plane $(001)$ where $\mathrm{n}=2 ; 4 ; 6[8]$.

Starting with the $\mathrm{Zn}_{0.9} \mathrm{Co}_{0.1} \mathrm{O}_{\mathrm{y}}$ sample, an increase in Co concentration is accompanied by the formation of metallic cobalt phase [9] with hexagonal structure ( $a=$ $2.5031 \AA, c=4.0605 \AA$ ) with the Curie temperature of $\mathrm{T}_{\mathrm{C}}=848 \mathrm{~K}$. The diffraction peak of metallic cobalt phase $\left(44.24{ }^{\circ} 2 \theta\right)$ demonstrates the rigorous orientation of clusters along axis of film growth. The intensity of the peak diminishes as the Co content exceeds 13 at. \%. This phenomenon results from the transition of the cobalt phase with hexagonal structure to the $\mathrm{Co}_{3} \mathrm{O}_{4}$ phase with cubic structure $(a=8.0837 \AA)$. The Co clusters oxidize gradually: a small amount of metallic cobalt phase is maintained up to 30 at. $\%$.

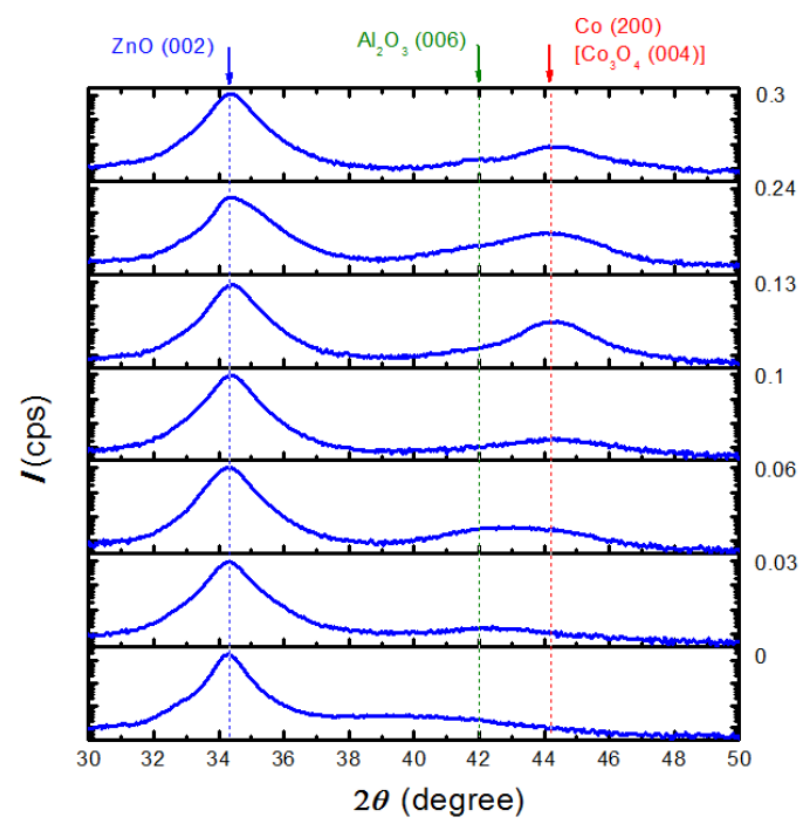

Fig. 1. The X-ray diffraction patterns of thin $\mathrm{Zn}_{1-\mathrm{x}} \mathrm{Co}_{\mathrm{x}} \mathrm{O}_{\mathrm{y}}$ films $(\mathrm{x}=0 \div 0.3)$.

It is found that an increase in Co concentration in $\mathrm{Zn}_{1-}$ ${ }_{\mathrm{x}} \mathrm{Co}_{\mathrm{x}} \mathrm{O}_{\mathrm{y}}$ thin film leads to reduction of the $c$-parameter of the crystal lattice. This fact is related to the tension of crystal lattice in the film plane which is caused by the different radii of substituted $\mathrm{Zn}$ and $\mathrm{Co}$ ions $\left(\mathrm{r}\left[\mathrm{Zn}^{2+}\right]=\right.$ $\left.0.074 \mathrm{~nm} ; \mathrm{r}\left[\mathrm{Co}^{2+}\right]=0.072 \mathrm{~nm}\right)[10]$.

The previous studies of transport properties [11] have shown that $\mathrm{Zn}_{1-\mathrm{x}} \mathrm{Co}_{\mathrm{x}} \mathrm{O}_{\mathrm{y}}$ films $(\mathrm{x}=0.2)$ have $n$-type conductivity, and electron concentration significantly decreases with growth of oxygen pressure. The figure $2 a$ represents the dependence of charge carrier concentration $n$ on the cobalt content $\mathrm{x}$ in thin $\mathrm{Zn}_{1 \text { - }}$ ${ }_{\mathrm{x}} \mathrm{Co}_{\mathrm{x}} \mathrm{O}_{\mathrm{y}}$ films.

The approximation of experimental values of electron concentration has shown the exponential reduction of $n$ with growth of the cobalt content in $\mathrm{Zn}_{1-\mathrm{x}} \mathrm{Co}_{\mathrm{x}} \mathrm{O}_{\mathrm{y}}$ films. Such dependence is related to increase in ionization energy of the donor state due to growth of energy of exchange interaction between electrons of the donor states and electrons of a $d$-state of cobalt ions [12].

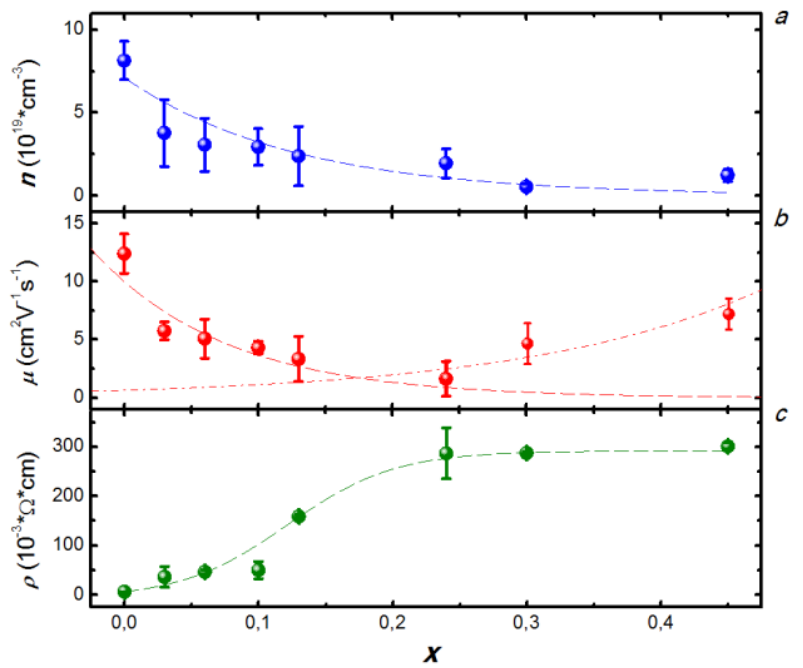

Fig. 2. The dependences of electron concentration $(a)$, mobility $(b)$ and resistivity $(c)$ in thin $\mathrm{Zn}_{1-\mathrm{x}} \mathrm{Co}_{\mathrm{x}} \mathrm{O}_{\mathrm{y}}$ on cobalt content $\mathrm{x}$.

It is obvious that high concentration of electrons in the samples synthesized in the oxygen depleted conditions is caused by high density of oxygen vacancies of $\mathrm{V}_{\mathrm{O}}$ [1] oxygen. The increasing of oxygen pressure in the chamber leads to essential reduction of vacancy concentration and to stoichiometric growth of $\mathrm{Zn}_{1}$. ${ }_{x} \mathrm{Co}_{\mathrm{x}} \mathrm{O}_{\mathrm{y}}$ films. Theoretical estimates $[13,14]$ showed that the energy levels of Co lie deeply in the band gap of zinc oxide therefore they can't be thermally activated and, consequently, participate in conductivity.

It is known what wurtzite wide gap semiconductors demonstrate low mobility of charge carriers. High density of oxygen vacancies in nonstoichiometric $\mathrm{Zn}_{1}$. ${ }_{\mathrm{x}} \mathrm{Co}_{\mathrm{x}} \mathrm{O}_{\mathrm{y}}$ films form the additional intracrystalline fields leading to reduction of charge carrier mobility. The dependence of charge carrier mobility $\mu$ on cobalt concentration $\mathrm{x}$ in $\mathrm{Zn}_{1-\mathrm{x}} \mathrm{Co}_{\mathrm{x}} \mathrm{O}_{\mathrm{y}}$ films is provided in a figure $2 \mathrm{~b}$. The mobility exponentially decreases at increasing in cobalt concentration up to 24 at.\% that is caused by degradation of crystalline lattice. The increasing of cobalt content to 30 at.\% the growth of mobility is observed. Probably, this phenomenon is associated with enhancement of anions in the films due to increasing of oxygen in the targets consisted from mixed powders $\mathrm{ZnO}$ and $\mathrm{Co}_{3} \mathrm{O}_{4}$. For example, in target contained 45 at. $\%$ of cobalt the part of oxygen is $10 \%$ higher, than in a pure target of $\mathrm{ZnO}$.

The field dependences of magnetization of $\mathrm{Zn}_{1-\mathrm{x}} \mathrm{Co}_{\mathrm{x}} \mathrm{O}_{\mathrm{y}}$ thin films were obtained at room temperature in the range of magnetic field \pm 1.6 T. Fig. 3 illustrates the field dependences of magnetization of $\mathrm{Zn}_{1-\mathrm{x}} \mathrm{Co}_{\mathrm{x}} \mathrm{O}_{\mathrm{y}}$ thin films. It is seen that the magnetic properties of $\mathrm{Zn}_{1-\mathrm{x}} \mathrm{Co}_{\mathrm{x}} \mathrm{O}_{\mathrm{y}}$ thin films change non-monotonically with the increase of the dopant concentration $[15,16]$. It has been revealed that $\mathrm{Zn}_{1-\mathrm{x}} \mathrm{Co}_{\mathrm{x}} \mathrm{O}_{\mathrm{y}}$ samples $(\mathrm{x}=0 ; 0.03 ; 0.1)$ are paramagnetics, while the other samples possess a weak ferromagnetism at room temperature. Although cobalt clusters start forming after cobalt reaches 10 at. $\%$, their quantity is not 
sufficient for the onset of ferromagnetic interaction. This factor explains paramagnetism of the $\mathrm{Zn}_{0.9} \mathrm{Co}_{0.1} \mathrm{O}_{\mathrm{y}}$ film.

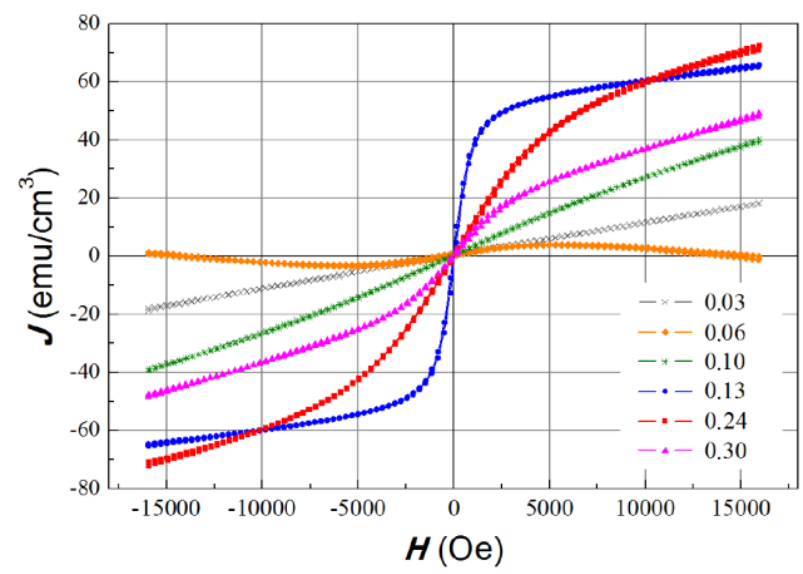

Fig. 3. The dependences of electron concentration $(a)$, mobility (b) and resistivity $(c)$ in thin $\mathrm{Zn}_{1-\mathrm{x}} \mathrm{Co}_{\mathrm{x}} \mathrm{O}_{\mathrm{y}}$ on cobalt content $\mathrm{x}$.

$\mathrm{Zn}_{0.87} \mathrm{Co}_{0.13} \mathrm{O}_{\mathrm{y}}$ thin film is shown to have the highest value of magnetic moment signal. The saturation magnetization for this sample is $J_{\mathrm{s}}=54.5 \mathrm{emu} / \mathrm{cm}^{3}$, and the coercive field equals to $H_{\mathrm{c}}=24.1 \pm 12$ Oe. Reduced saturation magnetization with cobalt concentration exceeding 13 at. \% (Fig. 3 ) is attributed to the combined ferromagnetic and paramagnetic contribution in the samples. The ferromagnetic response is explained by metallic cobalt clusters while paramagnetism is associated with the formation of cobalt oxide $\mathrm{Co}_{3} \mathrm{O}_{4}$ during $\mathrm{Co}$ oxidation. The increase in $\mathrm{Co}_{3} \mathrm{O}_{4}$ paramagnetic phase in thin films leads to the decrease in the ferromagnetic signal.

The structural, transport and magnetic properties of thin $\mathrm{Zn}_{1-\mathrm{x}} \mathrm{Co}_{\mathrm{x}} \mathrm{O}_{\mathrm{y}}$ films ( $\left.\mathrm{x}=0-0.45\right)$, fabricated on $c$ sapphire substrates by the pulsed laser deposition method are studied. It is found that the transport and ferromagnetic properties of the wurtzite $\mathrm{Zn}_{1-\mathrm{x}} \mathrm{Co}_{\mathrm{x}} \mathrm{O}_{\mathrm{y}}$ films nonmonotonously depend on Co concentration at room temperature. For the $\mathrm{Zn}_{0.87} \mathrm{Co}_{0.13} \mathrm{Oy}$ film, the strongest ferromagnetic signal is observed that is caused by formation of the greatest number of metallic Co clusters. It is shown that the oxygen deficiency significantly influence on transport and magnetic properties of thin $\mathrm{Zn}_{1-\mathrm{x}} \mathrm{Co}_{\mathrm{x}} \mathrm{O}_{\mathrm{y}}$ films.

The work was supported by the Federal Agency of Scientific Organizations (Agreement No 007-ГЗ/Ч3363/26) in part of films deposition and by the Russian Foundation for Basic Research (projects No. 16-29-05385, 16-07-00842, 16-29$11719,17-07-00615)$ in part films analysis.

\section{References}

1. H.J. Ko, T. Yao, Y.F. Chen, S.K. Hong, Appl. Phys. 92, 4354 (2002)

2. T. Dietl, H. Ohno, F. Matsukura, Science. 287, 1019 (2000)

3. M. Ivill, S.J. Pearton, S. Rawal, et al., New J. Phys. 10, 065002 (2008)
4. Y.Z. Peng, T. Liew, T.C. Chong, J. Appl. Phys. 98, 114909 (2005)

5. D. Chakraborti, S. Ramachandran, G. Trichy, et al., J. Appl. Phys. 101, 053918 (2007)

6. A.S. Kuz'mina, A.A. Lotin, O.A. Novodvorsky, N.S. Perov, E.A. Gan'shina, L.A. Makarova, A.S. Semisalova, A.G. Shneider, M.P. Kuz'min and S.S. Kolesnikov, Mater. Chem. Phys. 198, 291 (2017)

7. Q. Liu, C.L. Yuan, C.L. Gan, G.C. Han, J. Appl. Phys. 101, 073902 (2007)

8. A. Mecke, I. Lee, J.R. Baker jr., M.M. Banaszak Holl, B.G. Orr, Eur. Phys. J. E 14, 7 (2004)

9. Y.Z. Peng, T. Liew, T.C. Chong, W.D. Song, H.L. Li, W. Liu, J. Appl. Phys. 98, 114909 (2005)

10. N. Jedrecy, H. J. von Bardeleben, and D. Demaille, Phys. Rev. B. 80, 205204 (2009)

11. A.A. Lotin, O.A. Novodvorsky, V.V. Rylkov, D.A. Zuev, O.D. Khramova, M.A. Pankov, B.A. Aronzon, A.S. Semisalova, N.S. Perov, A. Lashkul, E. Lahderanta, V.Ya. Panchenko, Semicond., 48, 556 (2014)

12. V.G. Kytin, V.A. Kulbachinskii, D.S. Glebov, L.I. Burova, A.R. Kaul, O.V. Reukova Semicond., 44, 155 (2010)

13. A. Zunger, Sol. St. Phys., 39, 275 (1986)

14. J. Langer, C. Delerue, M. Lannoo, H. Heinrich, Phys. Rev. B. 38, 7723 (1988)

15. D. Chakraborti, S. Ramachandran, G. Trichy, J. Narayan, J.T. Prater, J. Appl. Phys. 101, 053918, (2007)

16. R. Al-Gaashani, S. Radiman, A.R. Daud, N. Tabet, Y. Al-Douri, Ceram. Int. 39, 2283 (2013) 